\title{
Paper Highlights
}

- No vehicle models are employed for generation of training data.

- Vehicles are tested in their normal operating environments.

- Road profiles are crudely measured yet of satisfactory frequency content.

- The methodology is tested for different vehicle speeds and road profiles. 


\title{
APPLICATION OF AN ANN-BASED METHODOLOGY FOR ROAD SURFACE CONDITION IDENTIFICATION ON MINING VEHICLES AND ROADS
}

\author{
H.M. Ngwangwa, P.S. Heyns \\ Centre for Asset Integrity Management, \\ Department of Mechanical and Aeronautical Engineering, \\ University of Pretoria, 0002 Pretoria, South Africa. \\ Tel: +2712 420 2432; Fax: +2712 3625087 \\ E-mail: hngwangwa@gmail.com.
}

\begin{abstract}
An artificial neural networks-based methodology for the identification of road surface condition was applied to two different vehicles in their normal operating environments at two mining sites. An ultra-heavy haul truck used for hauling operations in surface mining and a small utility underground mine vehicle were utilised in the current investigation. Unlike previous studies where numerical models were available and road surfaces were accurately profiled with profilometers, in this study, that was not the case in order to replicate the real mine road management situation. The results show that the methodology performed very well in reconstructing discrete faults such as bumps, depressions or potholes but, owing to the inevitable randomness of the testing conditions, these conditions could not fit the fine undulations present on the arbitrary random rough surface. These are better represented by the spectral displacement densities of the road surfaces. Accordingly, the proposed methodology can be applied to road condition identification in two ways: firstly, by detecting, locating and quantifying any existing discrete road faults/features, and secondly, by identifying the general level of the road's surface roughness.
\end{abstract}


Keywords: Mining haul roads, Displacement Spectral Density, Road roughness classification, Artificial neural networks, Road profile reconstruction, road condition monitoring.

\section{Introduction}

Current management techniques for the maintenance of mine haul roads, such as ad hoc blading, scheduled blading and maintenance management systems, have shortcomings in complex mining environments $[1,2,3]$. Too little road maintenance leads to excessive cost in the operation and maintenance of vehicles, whereas excessive road maintenance leads to greater cost but does little to reduce the cost of the operation and maintenance of vehicles [3]. Haul roads are subjected to variable traffic volumes, vehicle types and payloads. The standard systems for the management of haul-road maintenance are, in general, poorly suited to dealing with these complex and dynamic environments. Model-based road classification techniques have a greater potential to be very powerful, especially in an environment where details of the road characteristics are required $[4,5]$.

Road surface monitoring is one of the key functions of road maintenance management. A World Bank study [6] reports that the operating cost of vehicles and the cost of transporting goods rise as road roughness increases. Moreover, as the total operating cost of all vehicles on a road typically outweigh the agency's cost of maintaining the road by tenfold to twenty-fold, minor improvements in roughness could yield high economic returns. In this paper, an artificial neural network (ANN) is used for estimating the condition of a road surface by giving approximations 
of its profiles and their roughness classes by means of Displacement Spectral Densities (DSDs) $[7]$.

The impetus for this study came from the seminal work of Thompson and Visser [1] where mine haul road management systems were developed and the need for the development of real-time maintenance and management systems was identified. Thompson, Visser, Miller and Lowe [2] attempted to lay the foundations of such a real-time management system by employing a vehicle vibration signature analysis technique, but the output was purely qualitative since it could not estimate the extent of the severity of road damage. Later, Hugo, Heyns, Thompson and Visser [3] developed a methodology for reconstructing the road profiles via an inversion of the vehicle numerical model. Though the approach offered practically acceptable approximations of road damage, it was onerous since it involved complex system characterization. Consequently the use of black box models, such as an artificial neural network where system characteristics would not be required, was deemed appropriate.

This paper is therefore part of a series of works on the investigation of ANN-based methodology for monitoring the condition of the road surface. The work was undertaken in three main phases. The first phase $[7,8]$ consisted of applying the methodology to a numerical model which was simulated on artificially generated road profiles. The road profiles were generated by using a random function for calculating the road surface. Although the operating conditions were changed by varying the vehicle speeds, the payloads and by adding noise of different levels to the neural network inputs, everything was known and well-controlled. As a result, the ANN was trained and simulated with well-conditioned model-generated data. The findings of this numerical experiment were that the reconstructed road profiles and their DSDs had very high levels of fit for accuracy and for correlation. 
The second phase [9] comprised the application of the methodology to an experimental Land Rover Defender 110, which is used for research into vehicle dynamics by the Vehicle Dynamics Group at the University of Pretoria. The Land Rover is permanently instrumented with sensors, has carefully controlled suspension properties, and was driven along specially constructed and accurately measured roads at Gerotek (a vehicle-testing facility located in Pretoria in South Africa). The vehicle's suspension characteristics were switched between ride and handling modes, and the vehicle speeds were also varied between $14.5 \mathrm{~km} / \mathrm{h}$ and $54 \mathrm{~km} / \mathrm{h}$. Different layouts of trapezoidal bumps and Belgian paving were used in the test. This study provided an opportunity to investigate further the performance of the methodology with different vehicle suspensions under controlled experimental conditions. The ANNs were trained by using vertical vehicle accelerations calculated by a numerical model of the Land Rover, simulated for variously altered versions of the test road profiles. The findings show that the quality of the reconstructed bumps is superior to that of the Belgian paving. The neural network performance for the Belgian paving was found to be better represented by the DSDs than the raw road profiles themselves.

In the present phase, the methodology has been evaluated in field tests where the road surfaces were not as accurately constructed and measured as those at Gerotek. This was to replicate the actual situation in public rural roads and mine haul roads condition monitoring where accurate profilometers are both inapplicable and unavailable for profile measurement. In addition, there was far less control over the operation of the vehicle than there had been for the experimental Land Rover, and no numerical vehicle models were available for the two vehicles. For these reasons, the training data was selected from the test data only. The greatest challenge with this selection was the scarcity of data due to the many unknown random operating conditions. A substantial number of tests and measurements would have had to be performed if the acquired 
data were to be completely representative of the vehicle's real dynamic behaviour under every available operating condition. Furthermore, though vehicle control is a key input into the vehicle-road interaction system, there is no simple way to measure it quantitatively. The inconsistencies in the vehicle control over different road conditions introduced drastic variations in the quality of the measured data, in this way affecting the representativeness of the underlying vehicle dynamics. However, these challenges are what have made the present investigation unique.

Sundin and Braban-Ledoux [10] assert that ANN applications to pavement management systems (PMS) have received significant attention since the early 1990s. From the outset these ANN applications have been used as support tools for management decision-making as they complement the already existing rule-based expert systems. Sundin and Braban-Ledoux [10] identify three principal areas for the application of neural networks to PMS: the first area involves estimating the current pavement condition $[11,12,13]$, the second, predicting the future pavement condition [14] and the third, assessing the pavement needs and selecting the best maintenance actions $[15,16]$. In the estimation of current and also the prediction of future pavement condition, the neural network utilizes as inputs the different pavement characteristics and as targets, the pavement performance indicators such as ride quality or surface distress. The pavement characteristics are obtained through visual inspections. These inspections are laborious and subjective, and are moreover often susceptible to high degrees of variability and systematic errors in the simulated results of the neural network, as introduced by different interpretations from different road experts. In the assessment of pavement needs and the selection of maintenance actions, the neural network uses the available data on pavement condition to identify the needs of the pavement and recommend the optimal maintenance actions. The 
application utilizes the neural networks in combination with rule-based expert systems [10]. In all three applications, the neural networks have been used as pattern classifiers where the network inputs have been obtained from typically subjective procedures.

In the present application, the inputs into the neural network were acquired through a more objective procedure where vertical vehicle accelerations were captured, using a computer-based data acquisition system. Furthermore, it was noted that, with a pre-trained neural network and for a given vehicle-road interaction system, the methodology could be implemented for a real-time road condition monitoring system. This paper shows that the methodology can be applied to vehicles operating in their normal environments with a minimal level of control during operation, and where the neural network is trained with barely sufficient data. Quite recently, two other groups of researchers used a similar approach and their preliminary results are quite encouraging. Kang, Lee and Goo [17] developed a road profilometer for unpaved courses by employing a momentum back-propagation neural network to estimate the road profiles. Yousefzadeh, Azadi and Soltani [18] demonstrate a methodology where the vertical vehicle accelerations are determined through an ADAMS model, and a static feed-forward neural network is used for estimating the road profiles.

Section 2 discusses the methodology that has been adapted to this practical application. It covers all the stages undertaken in the methodology, from vehicle and road selection up to the correlation of results. The organisation of the measured data is presented in Section 3. Section 4 presents and discusses the results and Section 5 gives the conclusions drawn from the study and makes recommendations, concluding the paper. 


\section{Methodology}

A complete layout of the methodology is shown as a flow chart in Figure 1. The process begins with the vehicle and road preparations and extends to the tools used for the correlation of results. The methodology itself starts with a description and an understanding of the vehicles and roads used for the test. In this study, the choice of the vehicles and roads was based on the availability of the vehicles and roads for the duration of the planned duration, the operational representativeness of the actual vehicle-road system, and the possibility of introducing artificial defects to the roads with minimal interference in the hauling operations. The vehicles were instrumented and the roads profiled in preparation for the measurement of the responses. After measuring the vertical vehicle accelerations, the data was pre-processed for ANN training and simulation. Finally, the classes of road roughness were determined from the ANN-simulated road profiles.

\subsection{The test vehicles and roads}

The ultra-heavy mine haul truck (Figure 2(a)) is commonly used in surface hauling and the small utility underground vehicle (Figure 2(b)) in underground operations. The haul truck's wheel-base measures about $5.7 \mathrm{~m}$ with a front height of $6.2 \mathrm{~m}$ and a tire diameter of $3.75 \mathrm{~m}$ (Figure 2(a)). It has four nitrogen-over-oil (hydro-pneumatic) suspension struts, each mounted above each wheel axle in front and linked at the rear by a trailing arm. This particular haul truck has a load carrying capacity of 300 tonnes. 
The small utility underground vehicle has a gross vehicle mass (GVM) of about 0.5 tonnes with a tire diameter of $0.7 \mathrm{~m}$. It has a wheel-base of $2.85 \mathrm{~m}$ and a vehicle width of $1.75 \mathrm{~m}$ (Figure 2(b)). It is below the average human height in order to allow for easy underground operation. It has a very low centre of gravity and does not have the bounce-pitch coupling problems that the haul truck has.

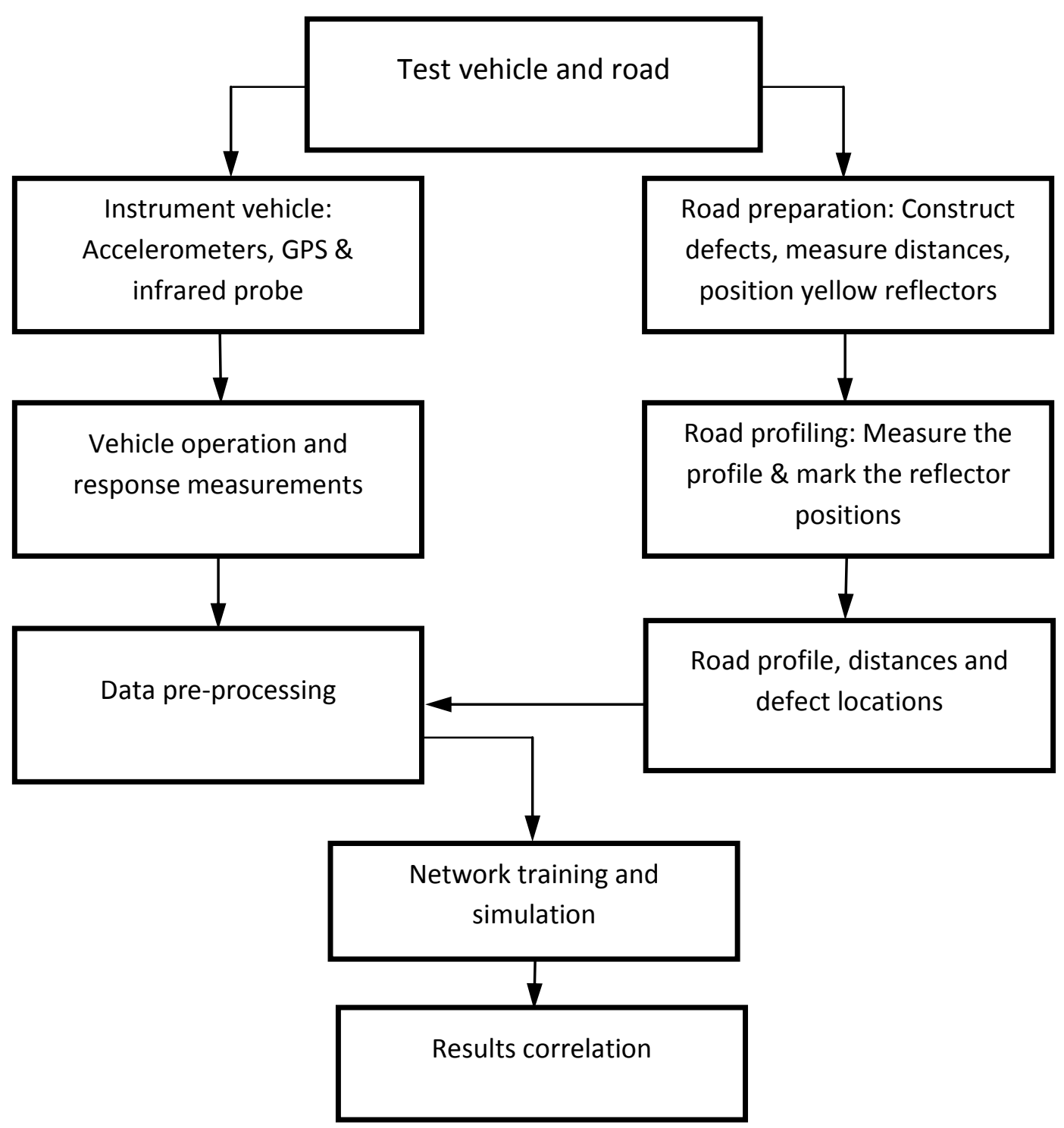

Figure 1. Flow chart summarising the methodology adopted in the test application. 

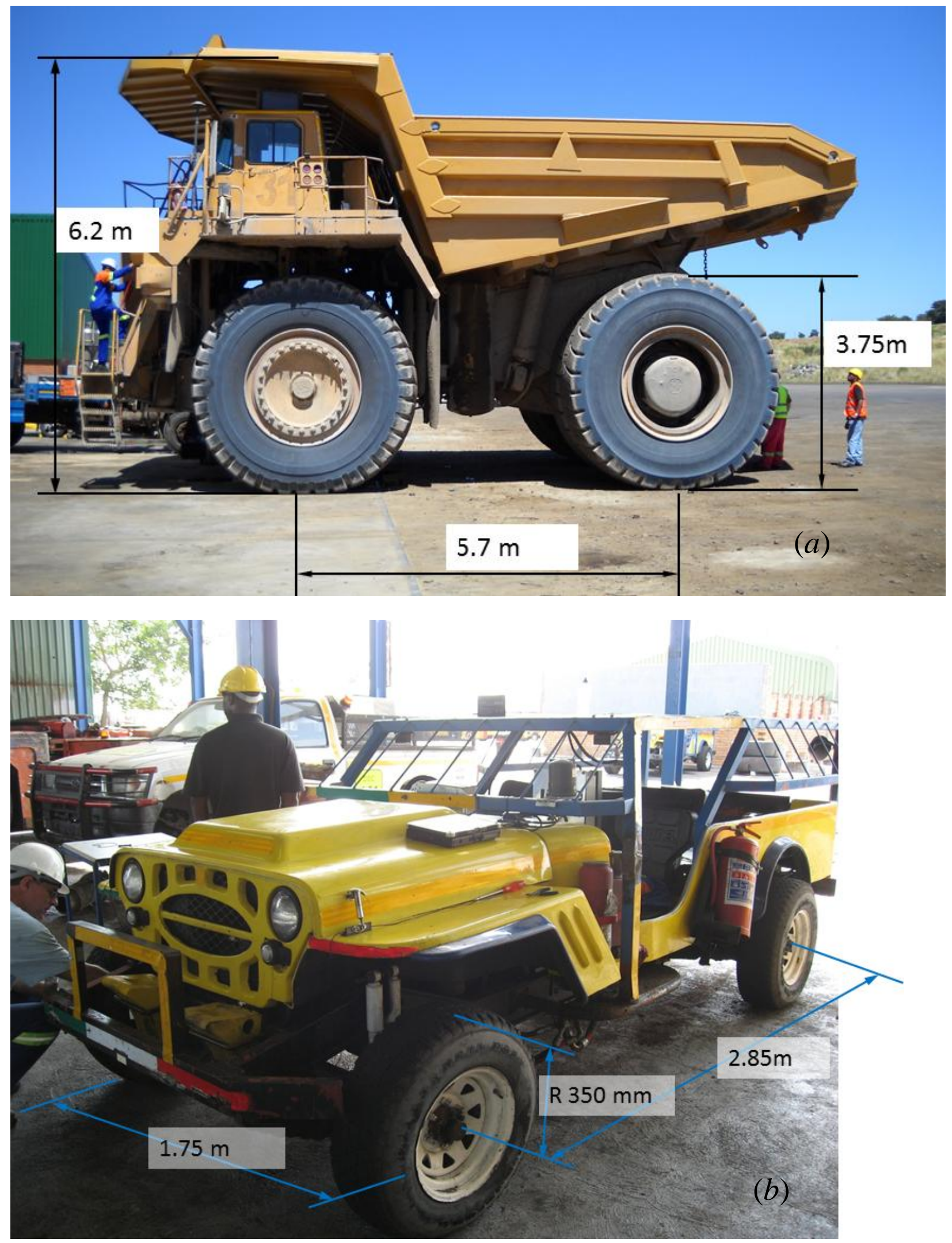

Figure 2. Haul truck (a) and small utility vehicle (b). 
The haul truck was tested on a typical haul road where three different forms of artificial defects were constructed. The defects were constructed by using a road grader. The small utility vehicle was tested on four different types of roads: a paved track with speed bumps, a gravel track with depressions, a coal-ash compacted smooth track with a brick bump and an underground track. All these test roads were selected from the existing road networks at the mine sites.

\subsection{Vehicle instrumentation}

The two vehicles were instrumented differently. The haul truck had two Crossbow tri-axial accelerometers, each mounted on either side of the front spindle. They were powered by a $12-\mathrm{V}$ battery which was affixed to the front bumper of the truck. An eDAQ-lite system was used as a data logger. A Panasonic Toughbook computer was used for data display and monitoring. The data was electronically transferred through the Toughbook computer to external storage. The infra-red position probe was used to identify the positions of the yellow reflectors that had been pasted along the road to mark the positions of the defects.

The small utility underground vehicle was instrumented with three Crossbow tri-axial accelerometers, two on the rear axle and the third on the front axle. A position probe was mounted on the front bumper to pick up the positions of the yellow reflectors positioned along the road. The vehicle speed was calculated from the measured rotational speed of the engine shaft and the given wheel-engine speed ratio. The engine speed was measured by a shaft encoder. An eDAQ-lite data logger and a Toughbook computer were also used for data acquisition. 


\subsection{Road preparation}

In the haul road tests, three different defects were constructed along the road. The position of each defect was accurately marked by pasting a single line of yellow strips at the start and double lines of yellow strips at the end of the defect. Then the truck was driven in the opposite direction to traverse the defects in a return mode. Though the measurements were taken over the entire road length, the data for training and simulation was extracted from each defect length only.

In the tests of the small utility underground vehicle, four different tracks were used: the first, was a 24-m long gravel track; the second, was a 24-m paved track; the third was a $10-\mathrm{m}$ coal-ash compacted smooth track where a brick bump was placed in the middle; and the fourth, was the underground track. This paper reports the results obtained for these two vehicles over the first two tracks only. Heyns, Heyns and De Villiers [4, 5] report the findings for the same vehicles over the brick bump and underground roads. Yellow strips were similarly used to mark the depressions along the gravel section and the two speed bumps on the paved road. The two ends of the test road sections were also clearly marked by the yellow strips.

\subsection{Road profiling and roughness classification}

In this study, the roads were not profiled by using standard road profilometers. Rules, poles and strings were used for measuring the profiles in both tests. A string was tied between two poles erected at the ends of a road section. The heights of the string from the ground were measured with a metre rule at different spacings, depending on the condition of the road surface. In both 
tests, the roads were sampled at $1 \mathrm{~m}$ except over the bumps and other important features where they were sampled at $0.25 \mathrm{~m}$. Figure 3 shows the simplified profiling set-up that was employed in this study.

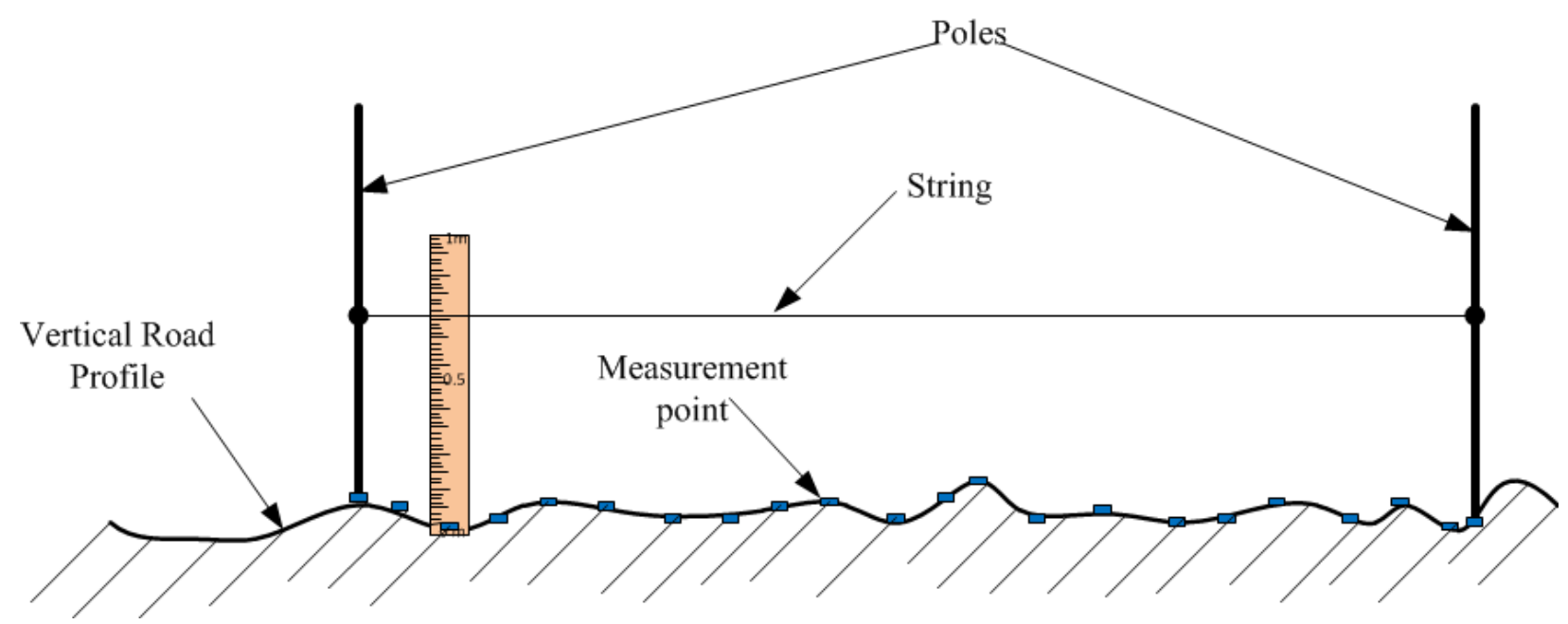

Figure 3. Simple road profile measurement.

The string in Figure 3 was regarded as a single variable. The height of the string at one pole was benchmarked as a reference point, hence that height was subtracted from each of the string heights at the other points along the road. The resulting values represent the deviations from the ground point at the selected pole. In order to determine the road profile, these deviations were simply sign-reversed. The profile data was stored as a data file that would be accessible in MATLAB for further processing. The other data that was recorded and saved, included the measurement points along the road and the positions of the yellow reflectors. This procedure has the main advantage of being simple and easy to perform without the need for specialised staff and equipment, and it is in line with most practices in the industry. However, it is understood by the investigators that it was performed at the expense of the accuracy of the measured profile. 
The proposed road roughness classification is based on smoothed form of displacement spectrum density of road profiles [19, 20] fitted with a straight line through the least-mean-square method in the spatial frequency range from 0.011 cycles $/ \mathrm{m}$ to 2.83 cycles/m [23]. However, this spatial frequency range was reduced to 1 cycle/m especially in haul truck tests since the distances were short and the vehicle was very large. The classification identifies eight road roughness levels ranging from class $\mathrm{A}$ to class $\mathrm{H}$ in increasing order of roughness. In the ISO classification [20], the fitted displacement spectral density $G_{d}(n)$ is given by

$G_{d}(n)=G_{d}\left(n_{0}\right) \cdot\left(\frac{n}{n_{0}}\right)^{-w}$

where $G_{d}\left(n_{0}\right)$ is the displacement spectral density calculated at the reference spatial frequency $n_{0}=0.1$ cycles $/ m ; n$ denotes spatial frequencies in cycles $/ m$; and $w$ is the exponent of the fitted displacement spectral density equal to 2 [19]. The subscript $d$ in the formula denotes that the calculated power spectral density is associated with displacement.

Figures 4 and 5 show averaged road profiles between the left and right wheel tracks, and their corresponding DSDs for the test on the haul truck and the test on the small utility vehicle. In the haul truck test, the DSD plots show that the waviness in the roads was dominated by spatial frequencies from 0.1 to 1 cycles/m corresponding to wavelengths from 1 to $10 \mathrm{~m}$. Accordingly, when the truck was travelling at the lowest nominal speed of $8 \mathrm{~km} / \mathrm{h}$, the road was capable of generating frequencies of excitation between 0.22 and $2.2 \mathrm{~Hz}$, and at the highest nominal speed of $34 \mathrm{~km} / \mathrm{h}$, the excitation frequencies ranged from 0.94 to $9.4 \mathrm{~Hz}$. 


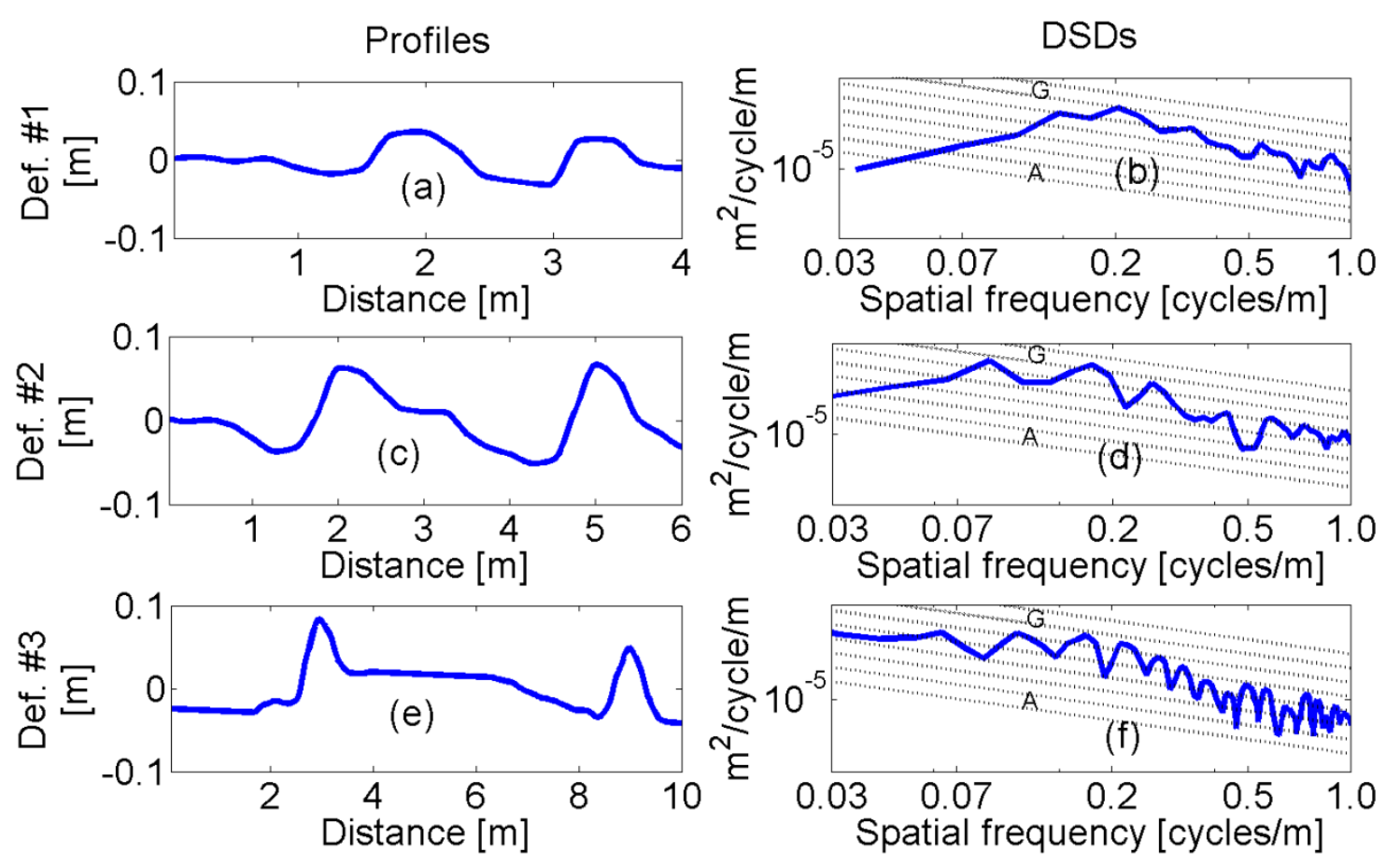

Figure 4. Averaged road profiles and PSDs in (a) and (b) for Defect 1, in (c) and (d) for Defect 2 and in (e) and (f) for Defect 3 during the mine haul truck test.

In the small utility vehicle test, Figure 5 shows the averaged gravel road profile in (a), its DSD in (b), the averaged paved road profile in (c) and its DSD in (d). By inspection, these tracks present a wider range of excitation frequencies. The depressions over the gravel track were due to surface degradation though the bumps over the paved track were actually speed bumps which had been constructed to check the vehicle speeds near the fuel pumps. Therefore these tracks have spatial frequencies in the entire range, as shown in Figure 5(b) and (d). When the vehicle was travelling at the nominal lowest speed of $6 \mathrm{~km} / \mathrm{h}$ and the highest nominal speed of $12 \mathrm{~km} / \mathrm{h}$, the corresponding temporal frequency ranges were: 0.25 to $8.3 \mathrm{~Hz}$ and 0.5 to $16.7 \mathrm{~Hz}$. Once again, the lower vehicle speeds did not sufficiently cover the unsprung mass frequencies which were expected to lie between 10 and $15 \mathrm{~Hz}$. 

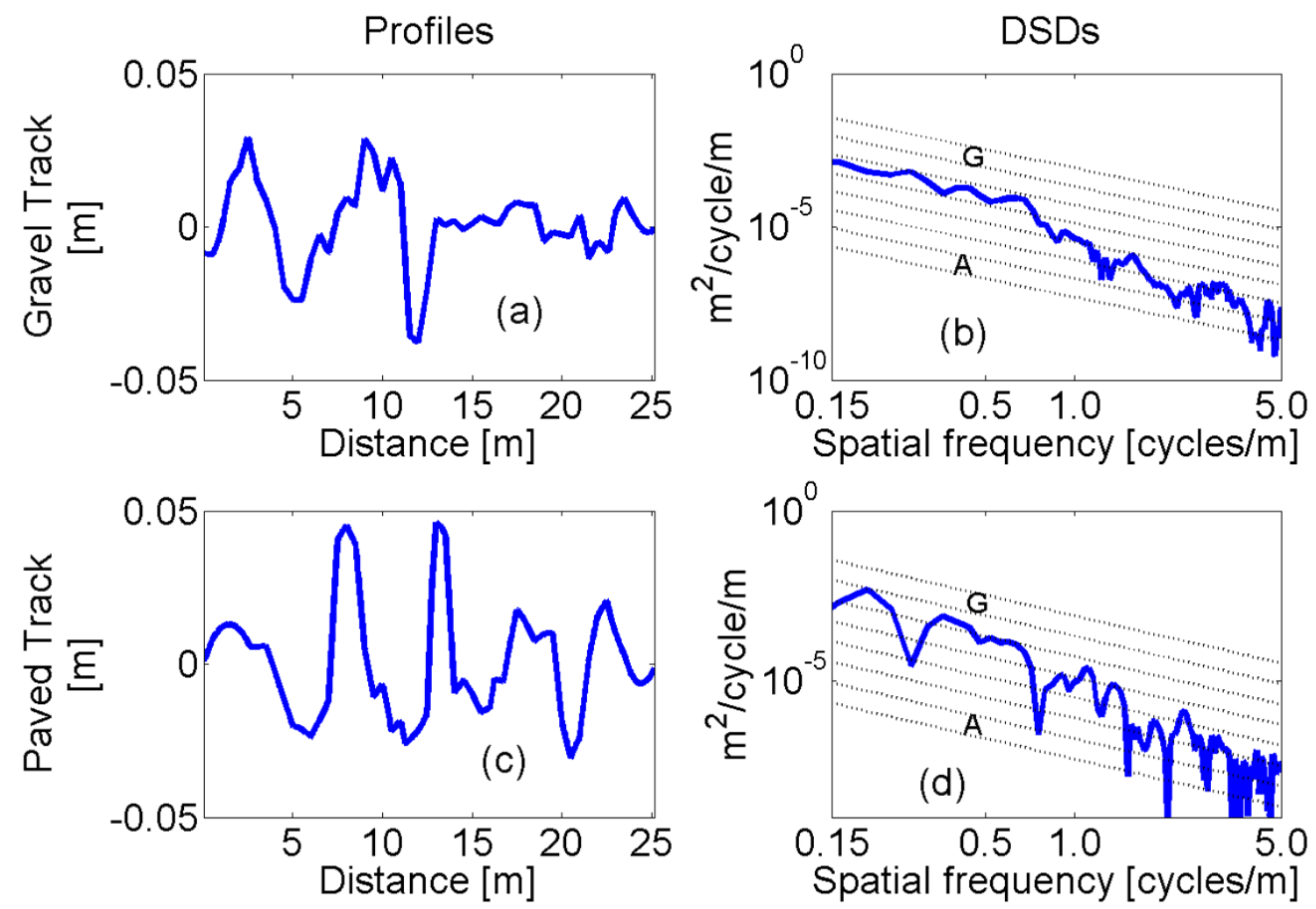

Figure 5. Road profiles and PSDs for the gravel road in (a) and (b); and for the paved road in (c) and (d).

\subsection{Vehicle operation and response data measurements}

For each of the two different tests, one driver was chosen to operate the vehicle throughout the testing period, to ensure some level of consistency in driving behaviour. The haul truck was tested in both an unloaded and a fully-loaded state. It was driven to and fro over the defects, in this way creating three more defects with reversed geometries. By contrast, the small utility vehicle was driven in one direction only, in a cyclic manner. The intention was that the haul truck should be driven at the nominal speeds of $8,12,18,28$ and $34 \mathrm{~km} / \mathrm{h}$ and that the speeds should remain constant throughout any particular test cycle. In the same way, the small utility 
vehicle was intended to be driven at the nominal speeds of $6,8,10$ and $12 \mathrm{~km} / \mathrm{h}$. However, subsequent analyses showed that there had been lapses during a particular test run where speed fluctuations were observed, and also across different test runs where it was observed that there had been no adherence to the given nominal speeds. For the haul truck, it was noted that any such loss of control during a particular test run led to the excitation of the pitch motion when the truck was travelling at speeds lower than $20 \mathrm{~km} / \mathrm{h}$. The haul truck showed no significant effects at the higher nominal speeds.

In both tests, the accelerations were measured on the axles as stated in Section 2.2. The accelerations were captured at a sampling frequency of $400 \mathrm{~Hz}$ with an upper cut-off point at a frequency of $250 \mathrm{~Hz}$. The data was recorded on a Somat eDAQ-lite data-acquisition system connected to the Toughbook computer used for monitoring the captured data. The integrity of the dc-coupled Crossbow accelerometers was verified on a high-frequency actuator and found to be highly accurate over the frequency range of interest [4].

\subsection{Data pre-processing}

The captured data were processed in MATLAB. As shown, the vehicle axle accelerations and road profile data were measured at different times, by different processes and at different sampling frequencies. This implies that there was a need for data alignment, filtering and resampling before the data could be used for ANN training. The positions of the yellow reflectors were used for aligning the eDAQ-lite data with the road profile data. This was done manually in MATLAB by using the ginput function [21]. This function gathers the co- 
ordinates of a point on a graph through a mouse input. Therefore the eDAQ-lite data corresponding to the stored road profile data was extracted by picking up the points on the eDAQ-lite data that marked the yellow reflectors at the START and END of each type of track. An allowance was made for the relative distances between the positions of the infra-red sensor and the response pick-up points in order to align the START and END points perfectly. Owing to the inevitable changes in vehicle travelling speeds, it was also necessary to consider aligning the other yellow reflectors near the defects.

After alignment, the eDAQ-lite data as well as the road profile data was resampled at $100 \mathrm{~Hz}$ and constant and linear trends in the data were removed. The acceleration data was low-pass-filtered at a cut-off frequency of $6 \mathrm{~Hz}$ for the haul truck and $30 \mathrm{~Hz}$ for the small utility vehicle. These cut-off frequencies covered the important vehicle frequencies and road wavelengths. However, the data had to be scaled to be applied to the ANN so that the inputs and targets fell within the same range. In both tests, the data was rescaled to the range [-1 1$]$ by using mapminmax in MATLAB [21].

\subsection{ANN identification and training}

The road-vehicle problem discussed in this paper is of a dynamic nature with non-linearities in the vehicle suspensions. Therefore, the Nonlinear AutoRegressive with Exogenous Inputs (NARX) [21] network presented in [7] was also used in this paper. However, there are some variations in the method of applying the NARX model in the present study. Unlike the earlier study [7], where the training and testing data were both acquired from numerical model 
simulations and the actual road profiles were readily available during the training and testing of ANN, in this investigation, actual road profiles are only available during network training. This is in line with a practical testing scenario where it may be desirable to estimate the road profiles from "unseen" vehicle axle accelerations. Therefore the series-parallel NARX model (newnarxsp) [21] was only used during training and then converted into a parallel configuration by using the MATLAB function sp2narx [21] for simulation purposes. The resulting model does not require the actual road profiles to be fed forward during simulation.

The ANN for the haul truck test is a 7-5-2 network, which implies that it has seven inputs with five tan-sigmoid neurons in the hidden layer and two linear neurons in the output layer. The seven inputs comprise: accelerations measured on the right-front and left-front axles, the calculated velocities and displacements, and the vehicle travelling speed. The velocities and displacements were further treated for low frequency drift by removing quadratic trends from the displacements and linear trends from the velocities. Ideally, the inclusion of the velocities and displacements as inputs do not affect the quality of the correlation between simulated and actual profiles, but these so-treated displacements and velocities were observed to give more stability to the training process in terms of number of iterations taken to converge to the targets. This is, however, an observation that requires further investigation and cannot be considered conclusive. In order to cater for different payload scenarios, the accelerations were further rescaled according to the ratio of the unloaded truck mass to approximate the fully loaded truck mass.

A 10-10-2 network was used for the small utility vehicle test, where the ten inputs comprise: accelerations measured on the right-rear, left-rear, and left-front axles; the numerically calculated velocities and displacements (similar to the haul truck case); and the vehicle travelling speed. 
There is no need for rescaling the accelerations due to payloads, since all the tests performed in the unloaded state. It was found that three delays in the input and feed-forward output were satisfactory for both neural networks. The number of neurons in the hidden layer was obtained through trial-and-error testing whereas the choice of tan-sigmoid activation functions was purely dependent on their superior performance in regression problems [21, 22, 23]. Since the network was intended to yield a profile for each wheel track, two neurons in the output layer were specified. The Levenberg-Marquardt algorithm (trainlm) was used as a training function [21, $22,23]$. It was chosen because of its superiority in solving regression problems and its computational efficiency, since it avoids the more costly evaluation of the Hessian matrix [23].

For any test in which the number of permutations of unique test scenarios is $\mathrm{R}$, and the sampling points in each test is $\mathbf{N}$, the input $(\mathbf{p})$ and target $(\mathbf{t})$ training data is organised as cell arrays in the form:

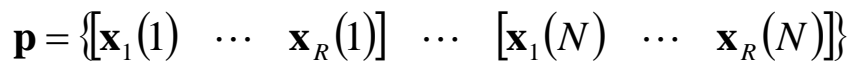

$$
\begin{aligned}
& \mathbf{t}=\left\{\begin{array}{lllllll}
\mathbf{y}_{1}(1) & \cdots & \mathbf{y}_{R}(1)
\end{array}\right] \cdots \quad\left[\begin{array}{llll}
\mathbf{y}_{1}(N) & \cdots & \mathbf{y}_{R}(N)
\end{array}\right\}
\end{aligned}
$$

where $\mathbf{x}_{i}(k)$ and $\mathbf{y}_{i}(k)$ are column vectors containing input and output elements respectively, for the $i$ th test scenario. Therefore in the case of the haul truck test, they are represented by,

$$
\begin{aligned}
& \mathbf{x}_{i}(k)=\left[\begin{array}{lllllll}
\ddot{z}_{u f f}(k) & \ddot{z}_{u l f}(k) & \dot{z}_{u f f}(k) & \dot{z}_{u l f}(k) & z_{u r f}(k) & z_{u l f}(k) & v(k)
\end{array}\right]_{i}^{T} \text { and, } \\
& y_{i}(k)=\left[\begin{array}{lll}
z_{r r} & z_{r l}
\end{array}\right]_{i}^{T} ; \text { where } \ddot{z}_{u f f}(k), \quad \ddot{z}_{u f f}(k), \dot{z}_{u r f}(k), \dot{z}_{u l f}(k), z_{u r f}(k), \dot{z}_{u l f}(k) \text { and } v(k) \text { are }
\end{aligned}
$$

the accelerations, velocities and displacements measured and calculated on the right-front and left-front axles, and the vehicle speed at the $k$ th sample point; and $z_{r r}$ and $z_{r l}$ are the road profile heights at the right and left wheel tracks respectively. The superscript $T$ denotes the transpose of 
the relevant matrix or vector. The input column for the small utility vehicle has ten elements, as previously mentioned in this section.

The network is prescribed to train for a total number of 100 epochs but generalisation stops the training process much earlier at around 25 epochs. Generalisation is achieved through the use of a performance function, msereg [21], that minimises the sum of the square errors of the weights and biases [21, 22]. It is said that this performance function produces smaller weights and biases in the network, and forces the network response to be smoother and less likely to overfit the training data [22]. The performance ratio is set to 0.5 , which implies giving equal weight to the mean square errors and the mean square weights.

During simulation, "unseen" inputs are applied to the trained neural network models. These inputs are processed in a manner similar to that for the training data. The network yields normalised profile heights which are converted back into their actual values. The roughness classes represented by DSDs are subsequently computed from the transformed road profiles [20, $24]$.

\subsection{Assessing the validity of the results}

As a final stage in the methodology, the ANN-simulated profiles are compared with actual road profiles. In this paper, the bias error and correlation coefficient were used for assessing how close the simulated profiles were to the actual profiles. 


\subsubsection{Bias error}

The bias is measured by using the root mean square error (RMSE), which is given by

$R M S E=\frac{y_{r m s}-t_{r m s}}{t_{r m s}} \times 100 \%$

where $y_{r m s}=\sqrt{\frac{\sum_{n=1}^{N} y_{n}^{2}}{N}} ; \quad t_{r m s}=\sqrt{\frac{\sum_{n=1}^{N} t_{n}^{2}}{N}} ; \mathrm{N}$ is the total number of sample points, and $y_{n}$ and $t_{n}$ are the $n$th ANN output value and target value, respectively. A value close to zero indicates little bias and that the reconstructed profiles are generally at the same levels of amplitude as the actual profiles. In this paper, RMSE values that were less than $25 \%$ were considered as being practically sufficient.

\subsubsection{Correlation of results}

This is a measure of profile-fitting accuracy. The correlation coefficient is determined by the relationship

$$
R=\sum_{n=1}^{N}\left(\frac{y_{n}-\bar{y}}{\sigma_{y}} \cdot \frac{t_{n}-\bar{t}}{\sigma_{t}}\right) /(N-1)
$$


where $y_{n}$ and $t_{n}$ are the nth neural network output and target values respectively; the quantities

$(\bar{y}$ and $\bar{t})$ and $\left(\sigma_{y}\right.$ and $\left.\sigma_{t}\right)$ are the means and standard deviations of the neural network output and target values; and the $n=1,2, \ldots, N$ represent the data sequence in the vectors $y$ and $t$. In this paper $\mathrm{R}$ values greater than 0.5 are considered as being good enough.

\section{Measured data and selection of training data}

This section presents the measured data from both tests. Section 3.1 presents the way that the data was organized and Section 3.2 presents the method employed for selection of training data.

\subsection{Organisation of the measured data}

The measured data for the haul truck test is classified as shown in Table 1 part (A). There are eleven test cycles, of which seven are for the unloaded haul truck. Test cycles (2) and (3) do not have data for the return test runs because the haul truck was not driven over the defects on return. The letters L, H and V appended to the test run numbers represent low, high and variable speed ranges, respectively. A test run is considered as being conducted at a low speed range if all its elements in the truck velocity vector are below $20 \mathrm{~km} / \mathrm{h}$ and vice versa for a test run in the high speed range. As test runs 3, 9 and 10 have elements in the velocity vector belonging to both ranges, however, they are labelled as variable speed test runs. 
During fully loaded truck testing, the speed ranges alternated between low and high ranges from test cycle (8) to (11). Test cycle (8) was discarded because the results were spurious. The analysis of the data from this test cycle shows that the acquired accelerations did not indicate the existence of the any of the defects shown in test cycle (10), which was conducted under very similar conditions.

Table 1. Summary of how measured data was organised

(A) HAUL TRUCK TEST

UNLOADED TRUCK

FULLY LOADED TRUCK

TEST CYCLE NOS.
(1)
(2) (3)
(4)
(5)
(6) (7)
(8) (9)
(10)
(11)

FORWARD

$\begin{array}{llllllllllll}\text { Defect } 1 & 1 \mathrm{~L} & 7 \mathrm{~L} & 10 \mathrm{~V} & 13 \mathrm{~L} & 19 \mathrm{~L} & 25 \mathrm{H} & 31 \mathrm{H} & 37 \mathrm{~L} & 43 \mathrm{H} & 49 \mathrm{~L} & 55 \mathrm{H}\end{array}$

$\begin{array}{llllllllllll}\text { Defect } 2 & 2 \mathrm{~L} & 8 \mathrm{~L} & 11 \mathrm{~L} & 14 \mathrm{~L} & 20 \mathrm{~L} & 26 \mathrm{H} & 32 \mathrm{H} & 38 \mathrm{~L} & 44 \mathrm{H} & 50 \mathrm{~L} & 56 \mathrm{H}\end{array}$

$\begin{array}{llllllllllll}\text { Defect } 3 & 3 \mathrm{~V} & 9 \mathrm{~V} & 12 \mathrm{~L} & 15 \mathrm{~L} & 21 \mathrm{~L} & 27 \mathrm{H} & 33 \mathrm{H} & 39 \mathrm{~L} & 45 \mathrm{H} & 51 \mathrm{~L} & 57 \mathrm{H}\end{array}$

\section{RETURN}

$\begin{array}{llllllllllllll}\text { Defect } 3 & 4 \mathrm{~L} & --- & --- & 16 \mathrm{~L} & 22 \mathrm{~L} & 28 \mathrm{H} & 34 \mathrm{H} & 40 \mathrm{~L} & 46 \mathrm{H} & 52 \mathrm{~L} & 58 \mathrm{H}\end{array}$

$\begin{array}{llllllllllllll}\text { Defect } 2 & 5 \mathrm{~L} & --- & --- & 17 \mathrm{~L} & 23 \mathrm{~L} & 29 \mathrm{H} & 35 \mathrm{H} & 41 \mathrm{~L} & 47 \mathrm{H} & 53 \mathrm{~L} & 59 \mathrm{H}\end{array}$

$\begin{array}{lllllllllllll}\text { Defect } 1 & 6 \mathrm{~L} & --- & --- & 18 \mathrm{~L} & 24 \mathrm{~L} & 30 \mathrm{H} & 36 \mathrm{H} & 42 \mathrm{~L} & 48 \mathrm{H} & 54 \mathrm{~L} & 60 \mathrm{H}\end{array}$

\begin{tabular}{llllllllllllll}
\hline $\begin{array}{l}A V E R A G E \\
\text { SPEED } \\
(\mathrm{km} / \mathrm{h})\end{array}$ & 16 & 9 & 8 & 12 & 11 & 28 & 35 & -- & 28 & 9 & 25
\end{tabular}

(B) SMALL UTILITY VEHICLE TEST

\begin{tabular}{lccccccccc}
\hline & $(\mathbf{1})$ & $\mathbf{( 2 )}$ & $\mathbf{( 3 )}$ & $\mathbf{( 4 )}$ & $\mathbf{( 5 )}$ & $\mathbf{( 6 )}$ & $\mathbf{( 7 )}$ & $\mathbf{( 8 )}$ & $\mathbf{( 9 )}$ \\
Gravel Road & 1 & 3 & 5 & 7 & 9 & 11 & 13 & 15 & 17
\end{tabular}


$\begin{array}{lllllllll}\text { Paved Road } & 2 & 4 & 6 & 8 & 10 & 12 & 14 & 16\end{array}$

AVERAGE

$\begin{array}{llllllllll}\text { SPEED } & 6 & 8 & 11 & 12 & 12 & 10 & 10 & 12 & 12\end{array}$

$(\mathrm{km} / \mathrm{h})$

The remaining ten test cycles had 24 different test scenarios derived from different combinations of truck load condition (unloaded or fully loaded); defect type (defect 1, defect 2 or defect 3); speed range (low or high); and travelling direction (forward or return). The condition of different truck loads is addressed by "weighting" the measured accelerations with the two different ratios derived from the respective approximate weights of the truck during an unloaded and fully loaded state. This reduced the number of possible test scenarios from 24 to 12 . Ideally the neural network should therefore be trained with 12 different sets of data, each representing a different test scenario. However, that holds true only if those 12 test scenarios are found to contain data that is linearly independent or not highly correlated.

Table 1 part (B) summarizes the test data for the small utility vehicle test. The presented data is from nine test cycles, each cycle comprising travelling first over the gravel road and then over the paved road, giving a total of 17 test runs, since the last cycle was not completed over the paved road. The nominal vehicle speeds are shown below each test cycle. Each test track is $24 \mathrm{~m}$ long. Since all the speeds are clustered within the same range (from $8 \mathrm{~km} / \mathrm{h}$ to $12 \mathrm{~km} / \mathrm{h}$ ) and the vehicle is unloaded throughout these tests, there are only two obvious test scenarios, i.e. tests over the gravel road and tests over the paved road. 


\subsection{Selection of training data}

The selection of training data is a crucial exercise owing to the desire to minimize computer training time in the presence of multiple candidates, as is the case for the haul truck test. The small utility vehicle test does not present as great a challenge because there are ideally only two obvious cases from which the training data can be selected, given that the vehicle speeds differ only marginally. Accordingly, only the haul truck test data is discussed in this section.

The ANN may require 12 different sets of training data in order to achieve generalization over all possible different scenarios for the haul truck test if these test scenarios comprise data that is linearly independent. A number of different tools may be used to check linear the dependencies in data, but in this study, the Pearson's correlation coefficient implemented in MATLAB [21] by the function corr was employed. In addition to the correlation coefficient matrix which indicates correlation between two column vectors, corr also returns a matrix of p-values for testing the hypothesis of no correlation against the alternative that there is a non-zero correlation [21]. Each element in the matrix is the p-value for the corresponding element in the correlation coefficient matrix. Any two given data sets are considered insignificantly correlated if an element in the p-value matrix is greater than 0.05 . 
Table 2. Number of training data combinations as determined by the use of p-values $>=$ 0.05

\begin{tabular}{|c|c|c|c|c|c|c|c|c|c|c|c|c|}
\hline $\begin{array}{l}\text { Training } \\
\text { Data Id. }\end{array}$ & $1 \mathrm{~L}$ & $31 \mathrm{H}$ & $8 \mathrm{~L}$ & $26 \mathrm{H}$ & $15 \mathrm{~L}$ & $27 \mathrm{H}$ & $16 \mathrm{~L}$ & $28 \mathrm{H}$ & $17 \mathrm{~L}$ & $29 \mathrm{H}$ & $18 \mathrm{~L}$ & $30 \mathrm{H}$ \\
\hline $1 \mathrm{~L}$ & & 0.08 & 0.57 & & 0.61 & 0.06 & & & & & & \\
\hline $31 \mathrm{H}$ & 0.08 & & & & & 0.26 & 0.63 & 0.99 & 0.87 & & & \\
\hline $8 \mathrm{~L}$ & 0.57 & & & & & & & & & & & 0.45 \\
\hline $26 \mathrm{H}$ & & & & & & 0.32 & 0.37 & & 0.99 & & & \\
\hline $15 \mathrm{~L}$ & 0.61 & & & & & 0.06 & & & 0.12 & 0.76 & & 0.25 \\
\hline $27 \mathrm{H}$ & 0.06 & 0.26 & & 0.32 & 0.06 & & 0.88 & 0.10 & 0.20 & 0.29 & 0.94 & 0.33 \\
\hline $16 \mathrm{~L}$ & & 0.63 & & 0.37 & & 0.06 & & & 0.27 & & & 0.96 \\
\hline $28 \mathrm{H}$ & & 0.99 & & & & 0.10 & & & & & 0.07 & \\
\hline $17 \mathrm{~L}$ & & 0.87 & & 0.99 & 0.12 & 0.20 & 0.27 & & & & 0.40 & \\
\hline $29 \mathrm{H}$ & & & & & 0.76 & 0.29 & & & & & & \\
\hline $18 \mathrm{~L}$ & & & & & & 0.94 & & 0.07 & $0 . .40$ & & & \\
\hline $30 \mathrm{H}$ & & & 0.45 & & 0.25 & 0.33 & 0.96 & & & & & \\
\hline $\begin{array}{l}\text { No. } \\
\text { Uncorr. }\end{array}$ & 4 & 5 & 2 & 3 & 6 & 10 & 6 & 4 & 7 & 3 & 3 & 5 \\
\hline
\end{tabular}


The possible training data combinations are shown in Table 2 where the last row shows the number of uncorrelated data sets (abbreviated as No. Uncorr.) for a given data set. In order to minimise the computational overheads during training, it is recommended that combinations should be chosen that have a few number of data sets such as: $\{8 \mathrm{~L}, 1 \mathrm{~L}, 30 \mathrm{H}\},\{26 \mathrm{H}, 27 \mathrm{H}, 16 \mathrm{~L}$, $17 \mathrm{~L}\},\{28 \mathrm{H}, 31 \mathrm{H}, 27 \mathrm{H}, 18 \mathrm{~L}\},\{29 \mathrm{H}, 15 \mathrm{~L}, 27 \mathrm{H}\}$, or $\{18 \mathrm{~L}, 27 \mathrm{H}, 28 \mathrm{H}, 17 \mathrm{~L}\}$. It was furthermore observed that the fewer the number of uncorrelated data sets (No. Uncorr.), the greater the influence of that data set in the combination. For example, in $\{26 \mathrm{H}, 27 \mathrm{H}, 16 \mathrm{~L}, 17 \mathrm{~L}\}, 26 \mathrm{H}$ has the highest influence with only three uncorrelated data sets whereas $27 \mathrm{H}$ has the least influence with a total of 10 uncorrelated data sets. When using this combination, therefore, data sets 27 and 17L (with a total of 7 uncorrelated data sets) may be dropped with a minimal risk of losing ANN performance. Therefore the results presented in Section 4 are based on the training data combination $\{26 \mathrm{H}, 16 \mathrm{~L}\}$.

\section{Results and discussions}

A total of 67 test results are presented here with 50 from haul truck tests and 17 from small utility vehicle tests. The accuracy of the simulation results for these two types of tests are presented in terms of the root mean square error (RMSE) and correlation coefficient (R), as given in equations (2) and (3), but both are expressed as percentages. The results of the haul truck tests are presented in Section 4.1 and section 4.2 presents the results of the small utility vehicle tests. 


\subsection{Haul truck tests}

The results for haul truck testing in Table 3 show that, except for a very few cases, bias errors lie below $25 \%$ and a good proportion of the test cases have their correlation coefficients above $50 \%$. These are very encouraging results, considering the size of the truck and the shapes of the defects under investigation. The truck size and that of its tires make it almost practically impossible to detect the presence of small discrete obstacles or high-frequency undulations. This truck attenuates all axle accelerations at frequencies higher than its wheel hop, which in a similar truck studied by Hugo et al. [3] is reported to be in the range between $3-4 \mathrm{~Hz}$. At the same time, the content of the low frequencies in the measured accelerations is limited by the lengths of the test profiles themselves, which are: $4 \mathrm{~m}$ long for defect 1, $6 \mathrm{~m}$ long for defect 2 and $10 \mathrm{~m}$ long for defect 3 .

For example, when the truck is travelling at the highest nominal speed of $34 \mathrm{~km} / \mathrm{h}$, it will be sensitive to a minimum road roughness wavelength of $\lambda_{\min }=v / f=34 /(3.6 \times 4)=2.4 \mathrm{~m}$, whereas at the lowest nominal speed of $8 \mathrm{~km} / \mathrm{h}$, the minimum detectable roughness wavelength is, $\lambda_{\text {min }}=8 /(3.6 \times 4)=0.6 \mathrm{~m}$. This implies that at the high truck speeds only a few wavelengths of surface roughness from $2.4 \mathrm{~m}$ to $4 \mathrm{~m}$ for defect $1,2.4 \mathrm{~m}$ to $6 \mathrm{~m}$ for defect 2 , and $2.4 \mathrm{~m}$ to $10 \mathrm{~m}$ for defect 3 , effectively contribute to the axle accelerations, with the result that the reconstructed profiles are relatively smooth. At the low truck speeds, the wavelengths start from $0.6 \mathrm{~m}$ which 
implies the participation of high frequencies in the axle accelerations, with the result that the reconstructed profiles have some undulations.

The results in Table 3 show that the neural network is capable of learning the geometry of defect 2 more accurately than of defect 1 and defect 3 . As the space between the two main bumps in defect 1 does not allow for a complete settling of responses from the first bump, the transient responses from the first bump have more impact on the responses over the second bump. This problem may be aggravated by the difficulties encountered with controlling the operating conditions when the haul truck was traversing these two bumps. In relation to defect 3 , defect 2 has a more compliant shape with smoothly blended transitions between adjacent curves. Defect 3 has rather more abrupt changes in gradients that may be more susceptible to instability during numerical integration. It is very encouraging to note from the results of the training data, however, that the bias error for defect 3 actually compares very favourably with that for defect 2 .

The results in Table 3 show the following order of accuracy in estimating the three defects: defect 2 in forward run, defect 2 in return run, defect 3 in return run, defect 1 in forward run, defect 3 in forward run and defect 1 in return run. The correlation coefficient results for defect 1 in the return run can benefit from re-training the ANN with a representative "defect 1 in return run" test data. Unfortunately this was observed to have so adversely affected the simulation results of the other defects that, despite an improvement in the performance of the ANN on defect 1 , there were significant decreases in its performance on the other two defects. This is an aspect of generalization that requires further investigation. 
Table 3. Summary of results showing defect type and fitting errors as measured by the root mean square error (RMSE) and the correlation coefficient (R).

\begin{tabular}{|c|c|c|c|c|c|}
\hline Defect 1 & & Defect 2 & & Defect 3 & \\
\hline $\begin{array}{ll}\text { Test } & \text { RMSE } \\
\text { Run } & (\%) \\
\text { No. } & \end{array}$ & $\begin{array}{l}\text { Correlation } \\
\text { Coeff., R } \\
(\%)\end{array}$ & $\begin{array}{ll}\text { Test } & \text { RMSE } \\
\text { Run } & (\%) \\
\text { No. } & \end{array}$ & $\begin{array}{l}\text { Goodness } \\
\text { of Fit, R } \\
(\%)\end{array}$ & $\begin{array}{ll}\text { Test } & \text { RMSE } \\
\text { Run } & (\%) \\
\text { No. } & \end{array}$ & $\begin{array}{l}\text { Correlation } \\
\text { Coeff., R } \\
(\%)\end{array}$ \\
\hline
\end{tabular}

\section{FORWARD}

\begin{tabular}{lllllllll}
\hline $1 \mathrm{~L}$ & 22.2 & 57.1 & $2 \mathrm{~L}$ & 8.9 & 65.2 & $12 \mathrm{~L}$ & 33 & -44.9 \\
$7 \mathrm{~L}$ & 5.5 & 63 & $8 \mathrm{~L}$ & 11.4 & 58.7 & $15 \mathrm{~L}$ & 27.6 & -31.2 \\
$13 \mathrm{~L}$ & 15.4 & 78.2 & $11 \mathrm{~L}$ & 8 & 56.6 & $21 \mathrm{~L}$ & 3.1 & 25.4 \\
$19 \mathrm{~L}$ & 19.1 & 63.3 & $14 \mathrm{~L}$ & 11.6 & 67.1 & $27 \mathrm{H}$ & 3.8 & 61.1 \\
$25 \mathrm{H}$ & 22.9 & -36.9 & $20 \mathrm{~L}$ & 6.2 & 63.6 & $33 \mathrm{H}$ & 10.4 & 62.4 \\
$31 \mathrm{H}$ & 9.8 & -10.1 & $26 \mathrm{H}$ & 3.3 & 89.1 & $45 \mathrm{H}$ & 65.2 & 40.2 \\
$43 \mathrm{H}$ & 9.1 & 25.2 & $32 \mathrm{H}$ & 11.4 & 85.9 & $51 \mathrm{~L}$ & 36.8 & 15.3 \\
$55 \mathrm{H}$ & 3.9 & 47.2 & $44 \mathrm{H}$ & 23.1 & 71.8 & $57 \mathrm{H}$ & 24.9 & 36 \\
--- & --- & --- & $50 \mathrm{H}$ & 19.9 & 74.2 & --- & --- & --- \\
--- & --- & --- & $56 \mathrm{H}$ & 23.9 & 85 & --- & --- & --- \\
\hline
\end{tabular}

\section{RETURN}

\begin{tabular}{lllllllll}
\hline $6 \mathrm{~L}$ & 5.6 & 29.7 & $5 \mathrm{~L}$ & 13.3 & 37.6 & $4 \mathrm{~L}$ & 14.5 & 13.4 \\
$18 \mathrm{~L}$ & 21.6 & 0.5 & $17 \mathrm{~L}$ & 15.6 & 66.3 & $\mathbf{1 6 L}$ & $\mathbf{4 . 3}$ & $\mathbf{5 1 . 3}$ \\
$24 \mathrm{~L}$ & 7.5 & 13.7 & $23 \mathrm{~L}$ & 6.9 & 63.3 & $22 \mathrm{~L}$ & 20.2 & 57.1 \\
$30 \mathrm{H}$ & 10.9 & 9.6 & $29 \mathrm{H}$ & 2.6 & 68.6 & $28 \mathrm{H}$ & 14.5 & 57.9 \\
$36 \mathrm{H}$ & 13.3 & -6.8 & $35 \mathrm{H}$ & 5 & 60.4 & $34 \mathrm{H}$ & 8.9 & 59.1
\end{tabular}




$\begin{array}{lllllllll}48 \mathrm{H} & 15.8 & 11.9 & 47 \mathrm{H} & 20.1 & 66.3 & 46 \mathrm{H} & 34.8 & 59.2 \\ 54 \mathrm{~L} & 12.5 & -18.1 & 53 \mathrm{~L} & 22.8 & 53.7 & 52 \mathrm{~L} & 1.8 & -3.9 \\ 60 \mathrm{H} & 6.2 & 43.9 & 59 \mathrm{H} & 22.7 & 77.1 & 58 \mathrm{H} & 73.7 & 18.7\end{array}$

The following three sections present the ANN simulation results for each defect. The test runs are identified simply by their numbers prefixed by the symbol "\#" and the letters L, H and V have been dropped for simplicity.

\subsubsection{Defect 1}

Figures 6(a) and (b) show the correlation plots of the actual and reconstructed profiles in the forward and return runs respectively. In Figure 6(a), Test runs \#1 and \#7 represent the road profiles reconstructed from low-speed truck data whereas Test runs \#25 and \#31 have been reconstructed from high-speed truck data. The road profiles from the high-speed truck data appear smoothed out due to the filtering effects at high speeds. In Figure 6(b), Test runs \#6 and \#18 for the return runs represent the simulations from the trucks at low speed whereas Test runs \#36 and \#60 represent those from the trucks at high speed. All the low-speed results have some undulations which can be attributed to the participation of short wavelengths in exciting the axle accelerations. Test run \#6 is flattened out over the second bump, presumably because the truck followed a different wheel track during the earliest stages of the test when the truck operator was still becoming familiar with the requirements of the test. The undulation over the second bump in Test run \#60 was most probably caused by the superposition of pitch and accelerations from the increased sprung mass reaction on the axle on the measured axle accelerations. The sprung mass 
bounce and pitch for the haul truck were coupled and observed to be excited when the vehicle was fully loaded. However, the results show that the two prominent bumps of the defect were correctly identified in both the forward and return runs. The slight errors in the locations of the bumps were caused by a combination of data alignment and resampling disparities prior to the ANN training and simulation.

Figure 6(c) shows the roughness classification for these reconstructed profiles compared to that of the actual road profile. All the test runs yielded similar roughness classifications between classes $\mathrm{D}$ and $\mathrm{E}$ for the spatial frequency range from 0.15 cycles $/ \mathrm{m}$ to 0.4 cycles $/ \mathrm{m}$, corresponding to wavelengths between $2.5 \mathrm{~m}$ and $6.7 \mathrm{~m}$. In the roughness classification plot, the dotted lines represent different roughness classes from A to G. In all the roughness plots presented in this paper, only classes A and G are labelled for the sake of convenience.

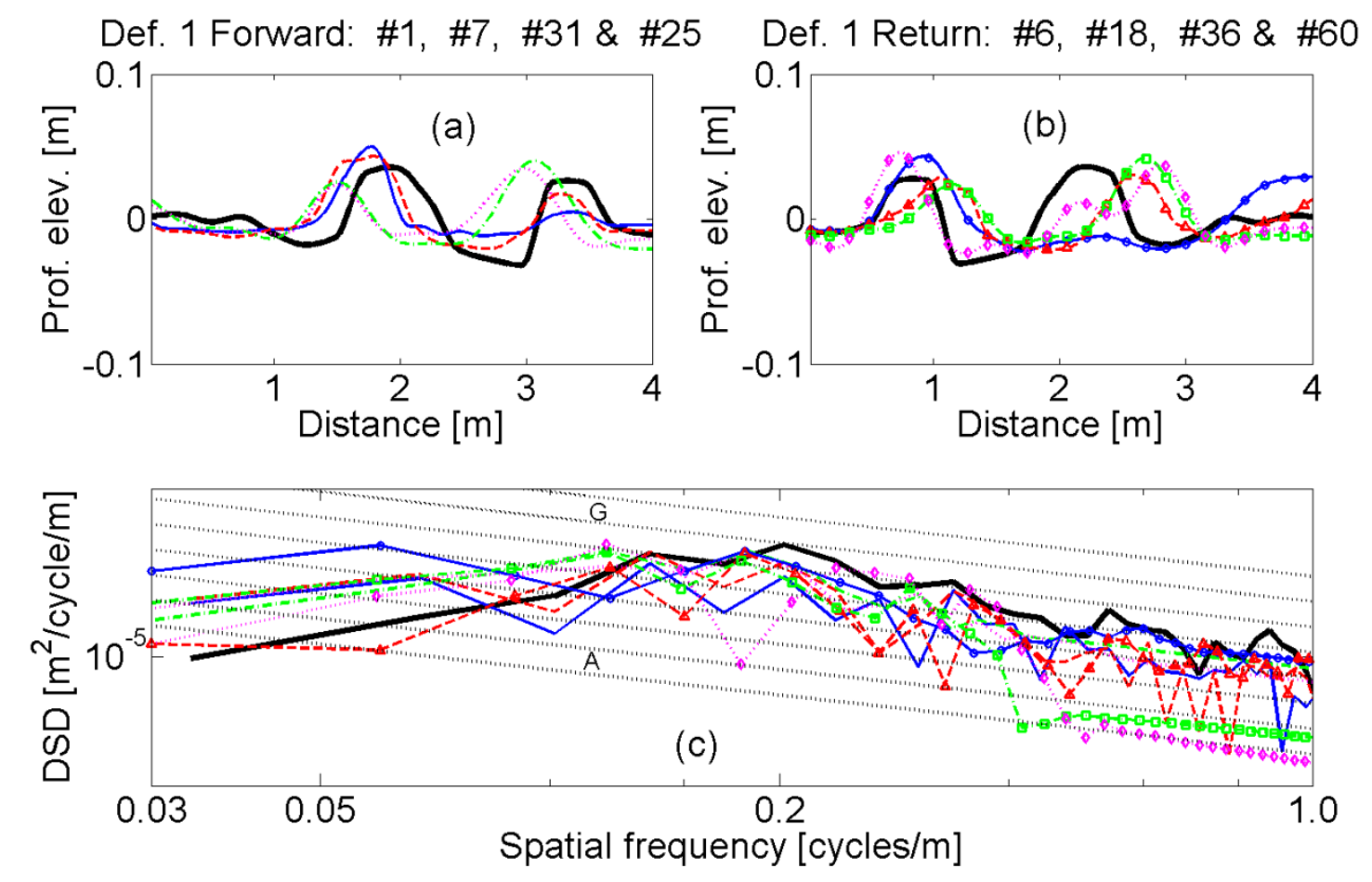

Figure 6. Correlations over Defect \#1 in forward run (a), in return run (b) and their corresponding DSDs (c): Actual, $\square$ \#1, - - - \#7, 


\subsubsection{Defect 2}

Figures 7(a) and (b) present the ANN simulation results for defect 2 in the forward and return runs, respectively. The results show an excellent correlation, particularly for Test runs \#32 and \#29, and all the other test runs correctly identify the two main bumps in this defect though there are variations in how they are able to reconstruct the intermediate saddle. Test runs \#32 and \#29 are both for an unloaded truck travelling at high speeds. The roughness classifications in Figure 7(c) show that defect 2 largely lies in the roughness classes between D and F. There is generally an excellent correlation in the roughness classifications from wavelengths of $2 \mathrm{~m}$ to $6.7 \mathrm{~m}$.
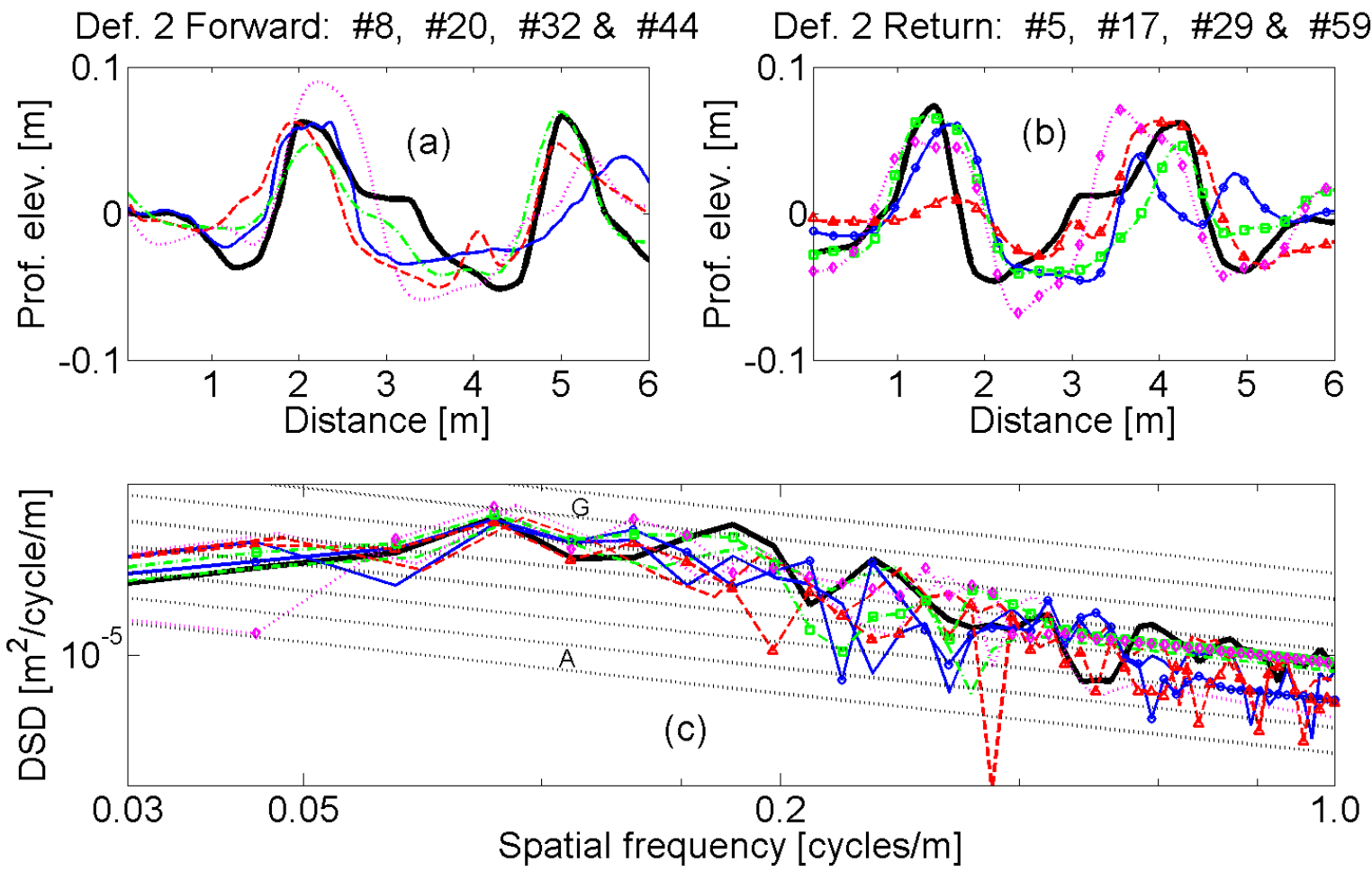
Figure 7. Correlations over Defect \#2 in forward run (a), in return run (b) and their corresponding DSDs (c): $\quad$ Actual, $\longrightarrow$ \#8, $--\quad$ \#20,

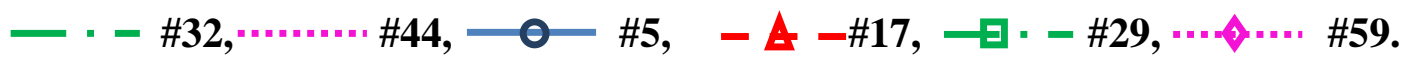

\subsubsection{Defect 3}

In Figures 8(a) and (b), Test runs \#27 and \#28 show an excellent correlation with the actual profiles, especially in identifying and locating the two prominent bumps in the profile. Both of these test runs are for an unloaded truck travelling at high speeds. The intermediate portion between the two bumps poses a challenge, in that the flat section and abrupt gradient changes introduce instabilities in the training algorithm, thus yielding a substantial number of undulations. The problem is actually aggravated in the unloaded truck, at low truck speeds in the return run, where the reconstructed profiles show very poor correlations. However, the road roughness classification in Figure 8(c) presents well-correlated DSDs of wavelengths between 2 $\mathrm{m}$ and $6 \mathrm{~m}$ for the actual and reconstructed profiles, irrespective of the poor correlations for the raw profiles themselves. 
Def. 3 Forward: \#12, \#21, \#27 \& \#45

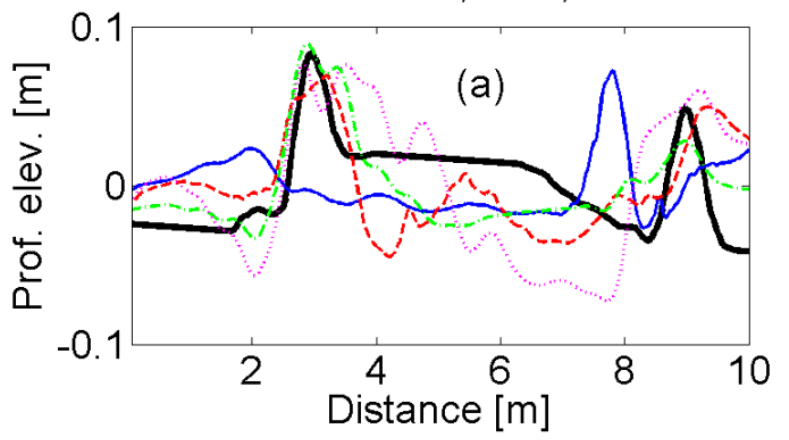

Def. 3 Return: \#22, \#4, \#28 \& \#58
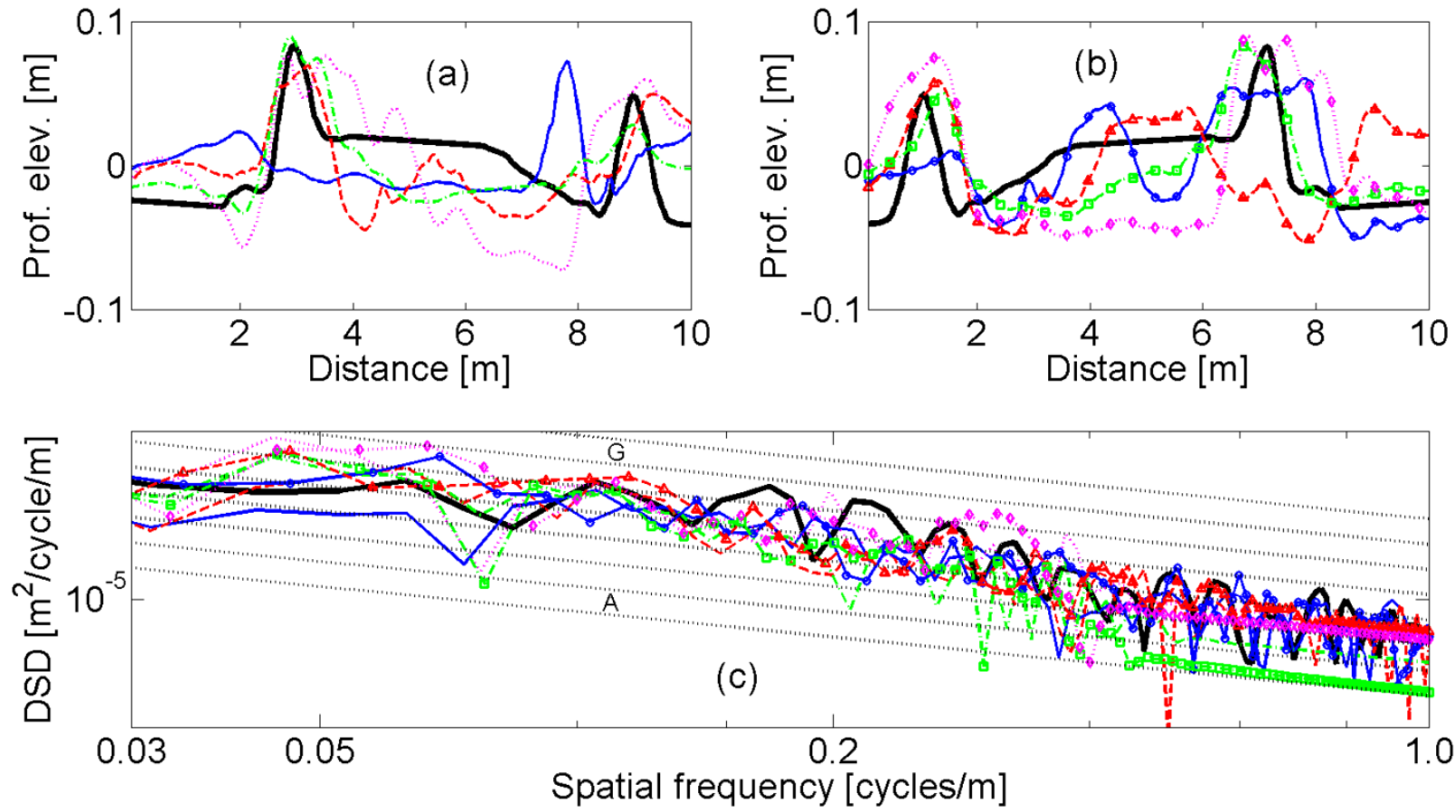

Figure 8. Correlations over Defect \#3 in forward run (a), in return run (b) and their corresponding DSDs (c): $\quad$ Actual, $\longrightarrow$ \#12, - - - \#21,

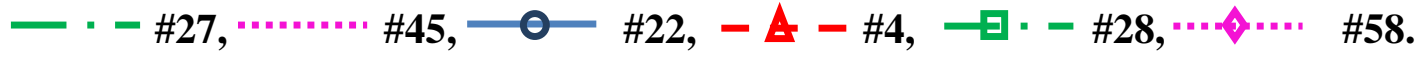

\subsection{Small utility vehicle for underground mining}

This vehicle and its tires are much smaller in size than the haul truck and therefore it does not pose similar problems to the haul truck, yet it has its own unique challenges. Its tire size and contact patch area make it responsive to shorter road roughness wavelengths. In addition, its unsprung mass resonance is much higher than for the haul truck. Consequently, unlike the haul truck where DSDs in the higher frequency ranges are largely underestimated by the ANN, the DSDs for the small utility vehicle are overestimated due to the errors introduced by the crude 
road profiling procedure as well as by the presence of high frequency noise in the ANN reconstructed profile. Consider the lowest speed of $6 \mathrm{~km} / \mathrm{h}$ with a vehicle whose wheel hop frequency is $15 \mathrm{~Hz}$. This vehicle is potentially sensitive to a minimum road roughness wavelength $\lambda_{\min }=6 /(3.6 \times 15)=0.11 \mathrm{~m}=110 \mathrm{~mm}$ and at the highest speed of $12 \mathrm{~km} / \mathrm{h}$, the minimum road roughness wavelength is $220 \mathrm{~mm}$. The shortest sample spacing during actual profiling is $250 \mathrm{~mm}$, which automatically excludes the shorter wavelengths and therefore fails to account for the higher frequency content in the measured axle accelerations. Though this problem is dealt with by resampling, aligning and filtering the measured accelerations and road profiles, it is difficult to achieve perfect alignment and filtering without roll-off effects.

The results in Table 4 show that only 6 out of 17 test runs have bias errors above $25 \%$ and 3 out of 17 test runs have correlation coefficients below 50\%. The results show that the ANN generally performs better over the gravel track than the paved track in this test. Although the results for the training data show that the paved track has a much lower RMSE at $2.3 \%$, there are four test runs with RMSE above $25 \%$ compared to only two test runs for the gravel track. The performance of the ANN around depressions and bumps contributes significantly to the differences in performance between the two tracks. As mentioned earlier, abrupt changes in gradients at and around certain profile sections make the ANN unstable, thus generating an augmented transient behaviour that cannot be sufficiently accounted for by the attendant profile geometry. In this test, the paved track profile had such sudden changes in profiles, especially around its bumps and depressions. Moreover, the paved track's harder surface made it harsher, especially at sufficiently high speeds, than the more flexible and tractable gravel track, which was wet on the day of the test. 
Table 4. Summary of results for the small utility vehicle.

Gravel Road Section

Paved Road Section

\begin{tabular}{cccccc}
\hline $\begin{array}{c}\text { Test Run } \\
\text { No. }\end{array}$ & $\begin{array}{c}\text { RMSE } \\
(\%)\end{array}$ & $\begin{array}{c}\text { Correlation } \\
\text { Coeff. R }(\%)\end{array}$ & $\begin{array}{c}\text { Test Run } \\
\text { No. }\end{array}$ & $\begin{array}{c}\text { RMSE } \\
(\%)\end{array}$ & $\begin{array}{c}\text { Correlation } \\
\text { Coeff. R }(\%)\end{array}$ \\
\hline 1 & 36.5 & 42.3 & 2 & 34.8 & 55.4 \\
3 & 27.2 & 56.7 & 4 & 14.5 & 64.4 \\
5 & 13.6 & 53.5 & 6 & 14.2 & 54.6 \\
7 & $\mathbf{1 0 . 7}$ & $\mathbf{6 6 . 4}$ & 8 & 27.1 & 68.6 \\
9 & 10.5 & 75.8 & 10 & 27 & 69.7 \\
11 & 20.2 & 65.3 & 12 & 29.1 & 39.5 \\
13 & 3 & 69.1 & $\mathbf{1 4}$ & $\mathbf{2 . 3}$ & $\mathbf{3 3 . 5}$ \\
15 & 2.2 & 66.9 & 16 & 6.4 & 50.5 \\
17 & 5.8 & 75.3 & --- & --- & -- \\
\hline
\end{tabular}

\subsubsection{Gravel road}

The results in Figure 9(a) show a good correlation between the actual and reconstructed profiles, except for Test run \#1 where the ANN locates depressions where there are no depressions. It is not known what might have caused this error. Test runs \#3, \#9 and \#17 follow the actual profile very well, locating all the important depressions, even though Test run \#3 underestimates the depressions and bumps. This underestimation may be due to the relatively lower speed at $8 \mathrm{~km} / \mathrm{h}$ of the small utility vehicle. This led to a corresponding underestimation of the DSDs, especially on the lower frequency end, as shown in Figure 9(b). The higher frequency end from 2 to 5 cycles $/ \mathrm{m}$ (wavelengths from $0.2 \mathrm{~m}$ to $0.5 \mathrm{~m}$ ) is overestimated by the ANN due to the disparities 
between the measured profile and acceleration data sampling rates. However, the DSDs correlate very well between 0.4 and 2.0 cycles $/ \mathrm{m}$ spatial frequencies for all the test runs.

Test Runs: \#1, \#3, \#9 \&\#17
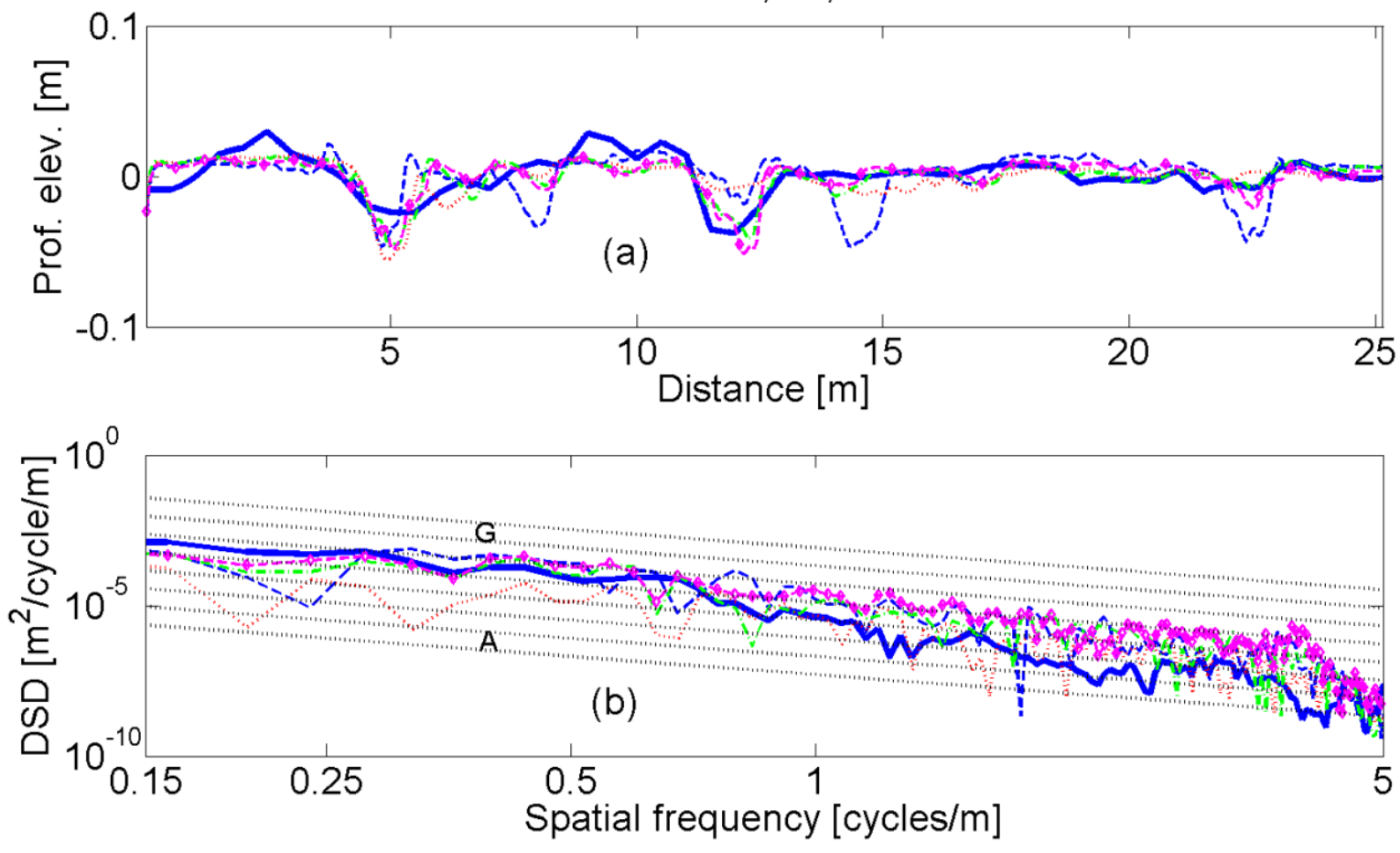

Figure 9. Comparison of actual with reconstructed profiles for Gravel Road Section (a)

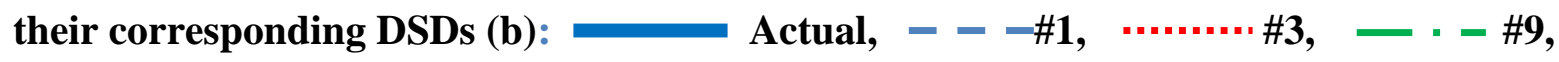
$\ldots \ldots \ldots \ldots$

\subsubsection{Paved road}

In Figure 10(a), Test runs \#2 and \#4 show a good correlation with the actual profiles whereas Test runs \#12 and \#16 have extra bumps over a depression before the first bump. Both of these test runs are at slightly higher speeds and the ANN tends to generate unstable results due to the 
nature of the profile in this region. As is the case with the gravel road tests, the DSDs are overestimated at the higher frequency end in Figure 10(b) but show very good correspondence within the same spatial frequency ranges from 0.25 to 2.0 cycles $/ \mathrm{m}$ which correspond to wavelengths of between $0.5 \mathrm{~m}$ and $4.0 \mathrm{~m}$.
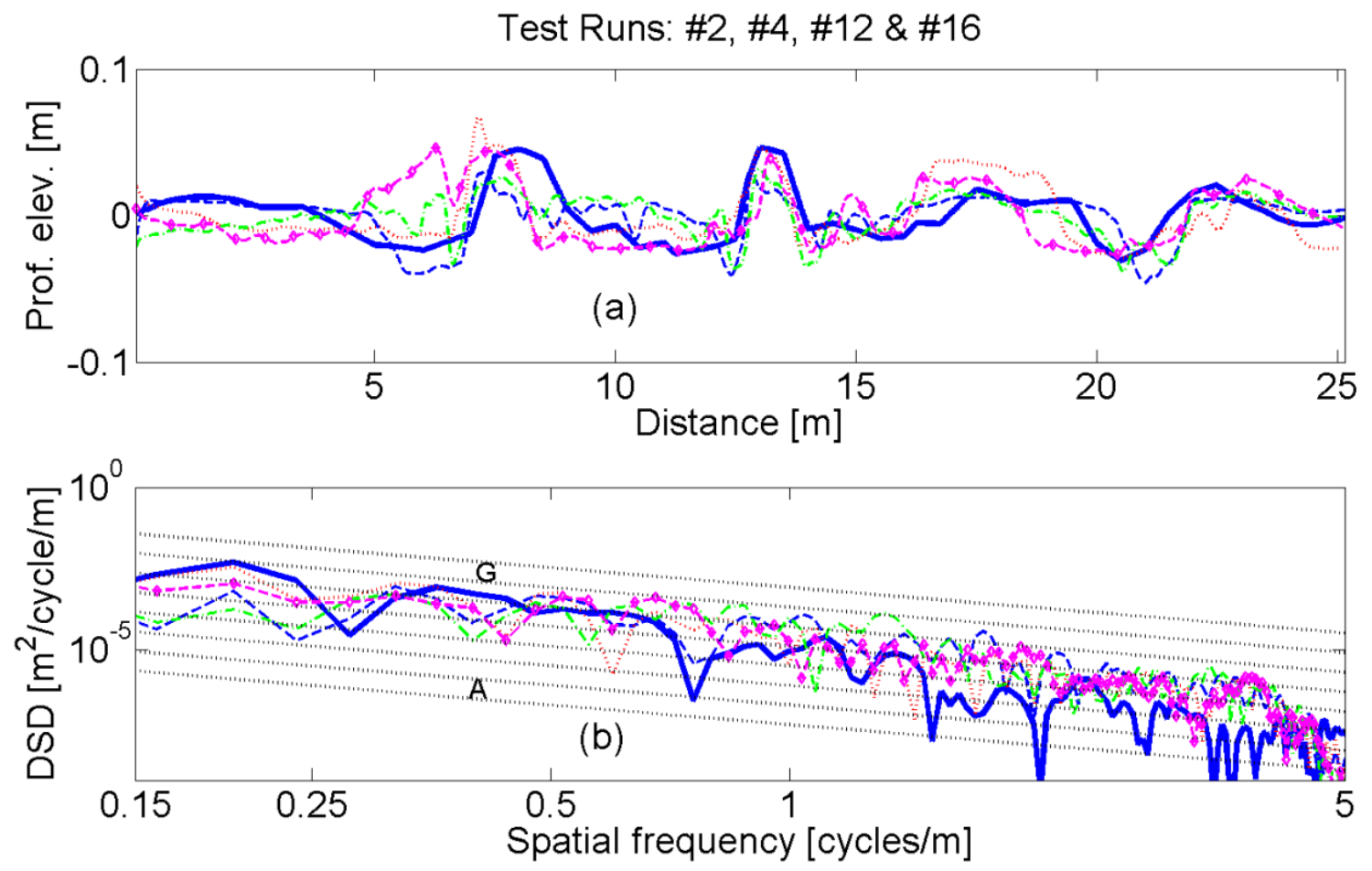

Figure 10. Comparison of actual with reconstructed profiles for Paved Road Section (a)

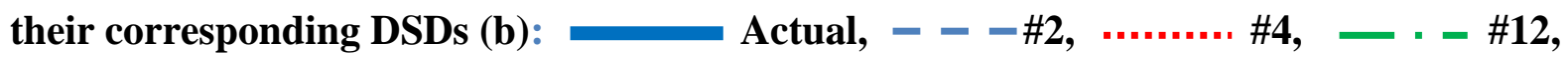
\#16. 


\subsection{Summary of test results}

The present paper indicates that the methodology has been applied successfully to the ultraheavy haul truck and small utility vehicle under normal operating conditions when exercising minimal control over their speeds only. The following points summarize the important findings obtained from the two tests.

- The ANNs yield good profile correlations, particularly with respect to identifying the prominent defects (i.e. bumps and depressions), on all road profiles for both tests. For the same ANN and vehicle type, the performance varies with the vehicle operating speeds and the geometry of the defects.

- In both tests, the ANNs are observed to perform better at high vehicle operating speeds than at low operating speeds. The reason is that, at the high speeds, enough dynamic energy is imparted to the vehicle structure while automatically eliminating the participation of non-essential short wavelengths from the test road profiles.

- The quality of the estimated DSDs is very good within the spatial frequencies between 0.15 and 0.5 cycles $/ \mathrm{m}$ (corresponding to wavelengths of 2.0 to $6.7 \mathrm{~m}$ ) for all defects in the haul truck tests and from 0.25 to 2 cycles/m (corresponding to wavelengths of 0.5 to $4.0 \mathrm{~m}$ ) for the small utility vehicle tests. These ranges of wavelengths are noted to be influenced by the size of the vehicle and its tires. Smaller vehicles and tires give relatively better DSD definition in the shorter wavelengths (or high frequency) ranges.

- The profile geometry influences the performance of the ANN. A gentler profile with perfectly blended geometry allows a better ANN performance than profile geometry with abrupt curvature changes. For the haul truck test, defect 2, which is observed to be gentler 
than defect 3, yields relatively better correlations. For the small utility vehicle, the less aggressive gravel track yields relatively better correlations than the harsher paved track.

- The correlation method used in selecting the training data-sets has worked very well in this application, but the ANN performance for defect 1 in the return run, in terms of correlation coefficients, imply that further refinement is required.

\section{Conclusions}

A methodology for road profile reconstruction and road roughness identification has been applied successfully to two vehicles at different mine sites, where the vehicles were tested in their normal operating environment. The present study sought to concretize the findings of the two previous studies performed, initially on the numerical vehicle model using numerically generated road profiles, and later, on an experimental vehicle with adjustable suspension to which accurately measured road profiles were applied. In the investigation of the numerical model, road profiles were reconstructed to very high levels of fitting accuracy under all simulation conditions. By contrast, in the investigation of the experimental vehicle, its performance was noted to be affected by two main factors, namely the scarcity of the training data and consistency in following similar wheel tracks. Despite such difficulties, this investigation still benefitted from the available numerical model of the vehicle and the accurately measured profiles. Accordingly, the present study has the following unique problems:

1. The non-availability of vehicle numerical models so that the training data does not benefit from data that can be easily generated from the model. 
2. Lack of control or minimal control over the operating conditions in the normal working environment of the test vehicles.

3. Lack of accurate road profiles. The profiles are measured by a procedure which is very crude yet practically sound.

4. Application to two characteristically different vehicles.

In view of these challenges, the findings summarized in Section 4.3 are highly encouraging and indicate that the methodology holds promise for practical application to road condition monitoring systems. Quite a large proportion of the tests yielded bias errors of less than $25 \%$ with correlation levels higher than 50\%. Generally the methodology provides two fronts in the monitoring of road condition: firstly, detecting and locating any prominent road profile features such as imminent potholes or bumps, and secondly identifying the general roughness condition of the road network, which is particularly useful where the road surface is becoming degraded by increased random roughness rather than by the size of discrete obstacles.

Caution should be taken regarding certain key issues when applying this methodology to a practical situation:

1. Vehicle speeds should be sufficiently high to allow for the participation of prominent road roughness wavelengths in the excitation of measured accelerations.

2. The profiles and measured accelerations should allow for easier alignment.

3. In order to assist with making a reliable decision about maintenance, the final results should come from averaged simulations so that some errors can be reduced.

4. Profiles should be smoothed out by running a type of moving average filter over the measured road profiles so that any abrupt profile changes can be eliminated. 
For further work, it is recommended that the methodology should be investigated on a fleet of vehicles to determine whether a general structure for a neural network could be developed. Secondly, the generalization capabilities of the ANN and the requirements for its improvement should be investigated. Thirdly, an investigation should be done on how to refine the procedure for the selection of training data, which is proposed in this paper.

\section{References}

[1] Thompson R.J., Visser A.T. Mine haul road maintenance management systems. The South African Institute of Mining and Metallurgy 2003; 303-312.

[2] Thompson R.J., Visser A.T., Miller R.E., Lowe N.T. Mine haul road maintenance management systems. The South African Institute of Mining and Metallurgy 2003; 263-271.

[3] Hugo D., Heyns P.S., Thompson R.J., Visser A.T. Haul road defect identification and condition assessment using measured truck response, Journal of Terramechanics 2008; 45 : 79 88.

[4] Heyns T., De Villiers J.P., Heyns, P.S. Consistent haul road condition monitoring by means of vehicle response normalization with Gaussian processes. Engineering Applications Artificial Intelligence 2012; 25:1752 - 1760.

[5] Heyns T., Heyns, P.S., De Villiers J.P. A method for real-time condition monitoring of haul roads based on Bayesian parameter estimation. Journal of Terramechanics 2012; 49:103 - 113.

[6] Paterson W.D.O. Road deterioration and maintenance effects: Models for planning and management. The Highway Design and Maintenance Standards Series. The International Bank 
for Reconstruction and Development/ The World Bank; Johns Hopkins University Press, Maryland USA 1987.

[7] Ngwangwa H.M., Heyns P.S., Labuschagne F.J.J., Kululanga G.K. Reconstruction of road defects and road roughness classification using vertical vehicle accelerations with artificial neural networks simulation. Journal of Terramechanics 2010; 47:97-111.

[8] Ngwangwa H.M., Heyns P.S., Labuschagne F.J.J., Kululanga G.K. An overview of the neural network based technique for monitoring of road condition via reconstructed road profiles. Proceedings of the $27^{\text {th }}$ Southern African Transport Conference (SATC 2008). 7-11 July 2008. Pretoria, South Africa.

[9] Ngwangwa H.M., Heyns P.S., Breytenbach H.G.A., Els P.S. Reconstruction of road defects and road roughness classification using Artificial Neural Networks simulation and vehicle dynamic responses: Application to experimental data. Paper under review at Journal of Terramechanics.

[10] Sundin S., Braban-Ledoux C. Artificial intelligence-based decision support technologies in pavement management. Computer-Aided Civil and Infrastructure Engineering 2001, 16(2), 143157.

[11] Attoh-Okine, N.O. Grouping Pavement Condition Variables for Performance Modeling Using Self-Organizing Maps. Computer-Aided Civil and Infrastructure Engineering 2001; 16 : $112-125$.

[12] Kaseko M.S., Ritchie S.G. A neural network-based methodology for pavement crack detection and classification. Transportation Research Part C 1993, 1(4), 275 - 291. 
[13] Banan M.R., Hjelmstad K.D. Neural networks and AASHO road test. Journal of Transportation Engineering 1996, 122(5), 358 - 366.

[14] Huang Y., Moore R.K. Roughness level probability prediction using artificial neural networks. Transportation Research Record 1997, 1592, 89 - 97.

[15] Goh, A.T.C. A hybrid neural network based pavement management system. Road and Transport Research 1997, 6(4), 62 - 71.

[16] Alsugair A.M., Al-Qudrah A.A. Artificial neural network approach for pavement maintenance. Journal of Computing in Civil Engineering 1998, 12(4), 249 - 255.

[17] Kang D.-K., Lee S.-H., Goo S.-H. Development of standardization and management system for the severity of unpaved test courses. Sensors 7 (2007) 2004-2027.

[18] Yousefzadeh M., Azadi S., Soltani A. Road profile estimation using neural network algorithm. Journal of Mechanical Science and Technology 2010, 24(3), 743 - 754.

[19] Andrén P. Power spectral density approximations of longitudinal road profiles. International Journal of Vehicle Design 2006, 40(1-3), 2 - 14.

[20] International Organization for Standardization ISO 8608: 1995(E), Mechanical vibration Road surface profiles - Reporting of measured data, 1995.

[21] Mathworks Inc., MATLAB Help Tutorial, 2007. Available online at http://filer.case.edu/pjt9/b378s10/nnet.pdf accessed on 26/06/2013.

[22] Bishop CM. Neural networks for pattern recognition, Oxford University Press, Oxford, 1995. 
[23] Hagan MT, Menhaj MB. Training feedforward networks with the Marquardt algorithm. IEEE Transactions on Neural Networks 5:6 (1994) 989-993.

[24] Cebon D. Handbook of vehicle-road interaction. Swets \& Zeitlinger Publishers, Lisse, 1999. 